NBER WORKING PAPER SERIES

\title{
THE EFFECT OF MEDICARE ADVANTAGE ON HOSPITAL ADMISSIONS AND MORTALITY
}

\author{
Christopher C. Afendulis \\ Michael E. Chernew \\ Daniel P. Kessler
}

Working Paper 19101

http://www.nber.org/papers/w19101

\author{
NATIONAL BUREAU OF ECONOMIC RESEARCH \\ 1050 Massachusetts Avenue \\ Cambridge, MA 02138 \\ June 2013
}

We would like to thank Dana Goldman for sharing his Part D Plan Characteristics file with us; Cheryl Sample at CMS for her rapid consideration of our data reuse request; seminar participants at Stanford, RAND, and USC for helpful comments; and Jack Boeglin for exceptional research assistance. We gratefully acknowledge funding from the National Institutes of Health. All errors are our own The views expressed herein are those of the authors and do not necessarily reflect the views of the National Bureau of Economic Research.

At least one co-author has disclosed a financial relationship of potential relevance for this research. Further information is available online at http://www.nber.org/papers/w19101.ack

NBER working papers are circulated for discussion and comment purposes. They have not been peerreviewed or been subject to the review by the NBER Board of Directors that accompanies official NBER publications.

(C) 2013 by Christopher C. Afendulis, Michael E. Chernew, and Daniel P. Kessler. All rights reserved. Short sections of text, not to exceed two paragraphs, may be quoted without explicit permission provided that full credit, including $(\mathcal{C}$ notice, is given to the source. 
The Effect of Medicare Advantage on Hospital Admissions and Mortality

Christopher C. Afendulis, Michael E. Chernew, and Daniel P. Kessler

NBER Working Paper No. 19101

June 2013

JEL No. I1,I13,I18

\begin{abstract}
$\underline{\text { ABSTRACT }}$
Medicare currently allows beneficiaries to choose between a government-run health plan and a privatelyadministered program known as Medicare Advantage (MA). Because enrollment in MA is optional, conventional observational estimates of the program's impact are potentially subject to selection bias. To address this, we use a discontinuity in the rules governing MA payments to health plans that gives greater payments to plans operating in counties in Metropolitan Statistical Areas with populations of 250,000 or more. The sharp difference in payment rates at this population cutoff creates a greater incentive for plans to increase the generosity of benefits and therefore enroll more beneficiaries in MA in counties just above versus just below the cutoff. We find that the expansion of MA on this margin reduces beneficiaries' rates of hospitalization and mortality.
\end{abstract}

\author{
Christopher C. Afendulis \\ Department of Health Care Policy \\ Harvard Medical School \\ 180 Longwood Avenue \\ Boston, MA 02115 \\ afendulis@hcp.med.harvard.edu \\ Michael E. Chernew \\ Harvard Medical School \\ Department of Health Care Policy \\ 180 Longwood Avenue \\ Boston, MA 02115 \\ and NBER \\ chernew@hcp.med.harvard.edu
}

\author{
Daniel P. Kessler \\ Stanford University \\ 434 Galvez Mall \\ Stanford, CA 94305 \\ and NBER \\ fkessler@stanford.edu
}


The welfare implications of public versus private production of publicly-financed services have been the subject of considerable debate (Shleifer 1998). Proponents of private production highlight the greater incentives for efficiency and greater ability to match services to individuals' preferences generally associated with markets. Opponents emphasize the problems associated with imperfect monitoring and the ability of private suppliers to avoid unprofitable clients.

This debate has become increasingly relevant as the country struggles to improve the operation of the Medicare program. Medicare, which provides publicly-financed health insurance to the elderly and disabled, is the second-largest (after Social Security) and the fastest-growing piece of the federal budget. This year, Medicare spending will be $3.7 \%$ of GDP, which is forecast to rise to 5.2\% of GDP by 2027 (Congressional Budget Office 2012). While the program has been successful in improving the lives of beneficiaries, it is also widely acknowledged to be highly inefficient, with some estimating that 20 percent of program spending is of questionable value (Skinner, Fisher, and Wennberg 2005).

Medicare currently allows beneficiaries to choose between a government-run health plan known as Traditional Medicare (TM), and privately-administered plans, known as Medicare Advantage (MA). Enrollment in MA has grown rapidly in recent years, now accounting for 27 percent of all beneficiaries and 22 percent of program payments (Kaiser Family Foundation 2012). The opposing views of private versus public production have been manifested in two distinct policy perspectives on MA. On one hand, MA plans may be better able to encourage physicians and hospitals to manage care appropriately, leading to lower costs and/or better health outcomes. On the other hand, MA plans may reduce welfare, by avoiding enrollment of sicker patients, stinting on care 
for sicker patients once they are enrolled, or incurring administrative costs that are disproportionate to their benefits.

Identifying the effects of MA on resource use and quality of care is thus of firstorder importance from the perspective of economics and national fiscal policy. But because enrollment in MA is optional, conventional observational estimates of the program's impact are potentially subject to selection bias. To the extent that beneficiaries who choose MA are unobservably healthier those who choose TM, conventional estimates of the effect of MA will represent some combination of the program's true causal effect and unobserved differences in its patient population.

In this paper, we offer a new approach to this problem. We use a discontinuity in the rules governing MA payments to private health plans that gives greater payments to plans that cover beneficiaries who live in counties that are part of Metropolitan Statistical Areas (MSAs) with populations of 250,000 or more. The sharp difference in payment rates at this population cutoff creates a greater incentive for plans to increase the generosity of benefits and therefore enroll more beneficiaries in MA in counties just above versus just below the cutoff. The induced incremental enrollment, in turn, allows us to identify the effect of MA on the use of medical services and the quality of care for the incremental enrollees. We find that the expansion of MA on this margin reduces Medicare beneficiaries' rates of hospitalization and mortality.

The paper proceeds in four parts. Part I provides background on the MA program and a summary of the vast academic literature on the effects of public versus private provision of publicly-financed health insurance. Part II describes our experimental design in detail and the data that we use to investigate the effects of MA relative to TM. Part III presents our econometric models and results, and Part IV concludes. 


\section{Medicare Advantage: Background and Previous Literature}

The Medicare program has a long history of private-sector involvement (see McGuire, Newhouse, and Sinaiko 2011 for an excellent and comprehensive review). Private insurance plans were introduced to Medicare starting in 1985 with the goals of expanding beneficiary choice and transferring to the Medicare program some of the efficiencies thought to have been achieved by managed care plans in the private sector. Enrollment in private Medicare plans has always been, and still is, optional for beneficiaries. Those beneficiaries who choose to enroll in a private plan continue to pay Medicare premiums to the government, equal to about 13 percent of the value of their benefits (CMS 2011, Table I.1). In return, they receive their coverage through (and may pay supplemental premiums to) an MA plan. MA plans receive from Medicare a predetermined monthly payment, adjusted for the demographic characteristics and health status of their enrollees.

There is a vast empirical literature that seeks to investigate the relative performance of MA and TM. This literature has three distinct parts. The best-developed arm compares the budget cost of MA to that of TM. The finding from this work is clear: MA spends more than would TM to cover a similar set of beneficiaries (MedPAC 2012a). In 2011, for example, MA spent $\$ 1.10$ for every dollar that would have been spent by TM; in 2012, the comparable figure is predicted to be $\$ 1.07$. This is all the more striking since the preponderance of evidence suggests that MA enrollees are on average healthier (MedPAC 2012b).

However, this anomaly is by design. Medicare pays MA plans as a function of a legislatively-determined rate called the "benchmark," and benchmarks are on average set well above what it would cost TM to coverage a comparable population. The Affordable 
Care Act (ACA) reduces MA payments, but they will still be more than TM, likely because it is immensely popular with beneficiaries: at least some of the extra payments to plans are passed back in the form of supplemental benefits.

Thus this work leaves two important questions unanswered: notwithstanding supplemental benefits, does MA consume more or less resources than TM, and is the care it provides of higher or lower quality? Researchers have sought to address the first of these questions by comparing rates of use of specific services available in both MA and TM, controlling for the demographic characteristics and health status of enrollees. This work generally finds that MA enrollees use fewer services, and experience more appropriate use, than do their counterparts in TM. For example, Landon et al. (2012) find that MA enrollees have fewer emergency-room visits, ambulatory surgeries, and inpatient admissions than comparable TM enrollees. Other work examines rates of readmission to the hospital (Lemieux et al. 2012, Cohen et al. 2012) and rates of admission for outpatient-care-sensitive illnesses (Basu and Mobley 2012), and finds them to be lower in MA as well.

Comparisons of the quality of care in MA versus TM have been more mixed. On one hand are the studies catalogued above that find lower rates of use of services in MA typically associated with inferior care (Kruzikas et al. 2000), which points to better quality of care in MA versus TM. Researchers have also found significantly lower mortality in MA versus TM (Dowd et al. 2011). On the other hand have been studies such as Keenan et al. (2009), which show that beneficiaries in MA self-report less favorable experiences with Medicare than comparable beneficiaries in TM, although more recent analysis by MedPAC (2012a) suggests that the gap between MA and TM plans on this dimension is shrinking. 
Yet, the research design of all of these studies suffers from an important limitation. They identify the effect of interest by comparing outcomes for beneficiaries who choose MA rather than TM, controlling for the observable differences between them. The assumption underlying this strategy -- that enrollees in MA are comparable to those in TM, conditional on observables -- is potentially problematic. There is evidence of favorable selection into MA on the basis of observables, and the model used to adjust payments to MA plans on the basis of observables explains only a fraction of the variation in beneficiaries' use of services (MedPAC 2012b). Because the unobservable characteristics of beneficiaries are likely positively correlated with the observables, the possibility remains that at least part of the estimated cost and quality advantage of MA over TM is due to unobserved differences in their covered populations rather than the true causal effects of the programs.

In addition, some related work finds that private health plans in the government's Medicaid program have been more costly and/or lower quality than their publicly-run analogue. Private plans were used in the Medicaid program by some states as early as the 1970s, but expanded dramatically after the passage of the Balanced Budget Act of 1997, which made it possible for states to require certain beneficiaries to enroll in managed care without obtaining a federal waiver. Two-thirds of Medicaid beneficiaries now receive most or all of their benefits through a private plan (Kaiser Family Foundation 2012). Duggan (2004) finds that the cost but not the quality of care increased in California counties after versus before they switched most Medicaid beneficiaries to private plans; Aizer, Currie, and Moretti (2007) use a similar identification strategy and find that the phase-in of Medicaid managed care reduced the quality of prenatal care and increased the rates of adverse birth outcomes. 
Findings from these studies of Medicaid are not necessarily generalizable. First, the low-income populations that they examine face challenges that the broader elderly population does not. Second, the data they use comes from California in the 1990s, which may not reflect the current state of private health plans nationally. Third, in California, Medicaid fee-for-service reimbursement rates (on which Medicaid managed care payments are based) are much lower than Medicare rates (Zuckerman, Williams, and Stockley 2009). Nonetheless, this work provides a cautionary note to the otherwise generally favorable assessment of MA from the observational analyses.

For these reasons, assessing the performance of MA remains an open empirical issue. In this paper, we offer a new approach to identifying its effects. We make use of a discontinuity in the benchmark rate on which Medicare's payments to plans are based. In the Benefits Improvement and Protection Act of 2000, Congress established "urban floors": minimum benchmarks, effective in 2001, for MA plans serving beneficiaries in counties that were part of MSAs with populations of 250,000 or more in 2000. Plans in smaller markets were paid lower rates. According to Pope et al. (2006), urban floors had a major impact on the program, causing plans to expand their benefits and widen their networks, thereby raising enrollment beyond what it would have otherwise been. Although the impact of floor rates has been examined in other work, no study to date has used the urban floor to identify the effect of MA on service use and quality of care. 


\section{Experiment and data}

To understand the nature of our experiment, it is necessary to understand the rules governing payment to MA plans. ${ }^{1}$ Plans bid to offer coverage, where the bid is to cover an average beneficiary. Medicare bases its payment to plans on the relationship between the bid and the benchmark (payments to plans are also adjusted for their enrollees' demographics and health). The benchmark is a publicly-disclosed, county-level number which is a function of several factors, including the county's average historical spending on TM beneficiaries. If a plan bids above the benchmark, enrollees must pay a premium equal to the difference between the bid and the benchmark. If a plan bids below the benchmark, it receives a "rebate" from Medicare equal to 75 percent of the difference, ${ }^{2}$ which it must pass back to beneficiaries in the form of supplemental benefits or premium offsets. Thus the existence of an urban floor in the benchmark rate creates a pseudorandom experiment: beneficiaries in counties subject to the urban floor are more likely to be offered plans with a higher benchmark relative to TM in the area and thus more generous benefits and/or lower premiums.

We study the utilization of services and quality of care for beneficiaries in the 449 counties that are part of MSAs with populations between 100,000 and 400,000 in 2000 . We compare outcomes from counties in MSAs with populations between 100,000 and 249,999 (not subject to the urban floor) to outcomes from counties in MSAs with populations between 250,000 and 400,000 (subject to the urban floor).

We use data from several sources. To construct the cohort of beneficiaries that we examine, we use data from the MedPAR, enrollment, and Part D Plan Characteristics

\footnotetext{
${ }^{1}$ This paragraph follows closely the explanation in MedPAC (2012c).

2 The 75 percent rebate which was effective in 2009 (our study period) has been decreased for subsequent years, and conditioned on plan's measured quality, by the Affordable Care Act.
} 
Files (all files come from the Centers for Medicare and Medicaid Services). MedPAR contains information on the inpatient hospital admissions of every Medicare beneficiary enrolled in TM, and since 2008, every beneficiary enrolled in MA. We match these data, at the beneficiary level, with data from the enrollment file, which contains information on demographic characteristics (age, gender, race, and county of residence) and whether the beneficiary was enrolled in MA or TM. For beneficiaries enrolled in MA, we determine the type of MA plan in which they enroll with the Part D Plan Characteristics File. With this information we construct a cohort of elderly beneficiaries (aged 65-99) who were enrolled in TM for all months of 2009 that they were alive, or enrolled in an HMO, Local PPO, or Regional PPO MA plan for all months of 2009 that they were alive. We exclude beneficiaries enrolled in other types of MA plans, in particular Special Needs Plans, Private Fee For Service Plans, and Employer Plans. These types of plans are characteristically different from other types of plans, and Special Needs and Employer Plan enrollees are characteristically different from other enrollees and subject to different payment rules.

We augment our primary data with information on counties from other sources. First, we obtained information on the county composition and population of MSAs from the Census Bureau website. ${ }^{3}$ Second, we obtained information on the characteristics of counties from the 2011 Area Resource File and the 2009 American Hospital Association survey. We did this to investigate the extent to which counties in MSAs above versus below the urban floor had similar incomes and numbers of physicians and specialists. Third, we constructed zip-code level measures of hospital market competitiveness (measured by a Hirschman-Herfindahl Index (HHI)) and the density of hospital market

\footnotetext{
${ }^{3}$ http://www.census.gov/popest/data/metro/totals/2009/.
} 
characteristics (for-profit/non-profit/public, teaching, system, and hospital-size status) using 2008 Medicare data according to the method in Kessler and McClellan (2000). Fourth, we obtained information from the CMS website on the composition of MA enrollment by plan type, ${ }^{4}$ the average risk score of MA enrollees, ${ }^{5}$ and the average risk score of TM enrollees ${ }^{6}$ to investigate the extent to which beneficiaries in counties above versus below the urban floor had similar health status. We match either the MA average risk score or the TM average risk score to each beneficiary based on his Medicare enrollment status.

Table 1 presents means and standard deviations of our outcome and control variables for all non-rural Medicare beneficiaries and beneficiaries from MSAs with population 100,000 - 400,000. For beneficiaries from MSAs in this population range, it also presents descriptive statistics by county floor status (in MSAs with above versus below 250,000 population), along with $p$-values from difference-in-means hypothesis tests (based on heteroscedasticity-robust standard errors clustered at the county level). The first row of the table shows that floor status affects incentives and MA enrollment in the way that a simple model would predict. Beneficiaries from counties above the urban floor threshold have a significantly higher benchmark payment rate (\$832) than do beneficiaries from counties below the threshold $(\$ 784)$, or about 6 percent. It is also true that beneficiaries from above-threshold counties are significantly more likely to enroll in MA -- 11.3 percentage points as compared to 6.1 percentage points, $p<0.001$.

\footnotetext{
${ }^{4}$ http://www.cms.gov/Research-Statistics-Data-and-Systems/Statistics-Trends-andReports/MCRAdvPartDEnrolData/Monthly-MA-Enrollment-by-State-County-ContractItems/CMS1224361.html.

${ }^{5}$ http://www.cms.gov/Medicare/Medicare-Advantage/Plan-Payment/Plan-Payment-DataItems/CMS1256179.html.

${ }^{6} \mathrm{http}: / /$ www.cms.gov/Medicare/Health-Plans/MedicareAdvtgSpecRateStats/FFS_Data.html.
} 
The next panel of the table presents average outcomes by floor status, and previews our analysis. On average, 16.8 percent of non-rural beneficiaries are admitted to the hospital at least once; the admission rate in our sample is slightly higher at 16.9 percent. This aggregate rate, however, masks an important difference in counties above versus below the floor threshold. Beneficiaries from above-threshold counties have an admission rate of 16.4 percentage points, whereas those from below-threshold counties have a rate of 17.3 percentage points. This difference of 0.9 percentage points, or approximately 5 percent, is statistically significant at the 1 percent level. The rate of admissions for conditions thought to be sensitive to appropriate outpatient care (referred to in the literature as ambulatory-care-sensitive (ACS) (Nicholas 2011) or preventable (Basu and Mobley 2012) admissions) is also statistically significantly lower in abovethreshold counties; although the difference is smaller in magnitude, it is proportionately almost twice as large. Mortality in the two groups is not statistically distinguishable at conventional levels.

If the above-threshold and below-threshold counties were otherwise similar, these results would imply that expansion of MA along the margin we examine leads to fewer hospitalizations but better (or at least no worse) health outcomes. In terms of most (although not all) important covariates, above- and below-threshold counties are not statistically distinguishable. The CMS risk scores for the two groups -- Medicare's best guess as to the groups' expected medical spending -- are virtually identical ( 0.975 versus 0.977). T-tests fail to reject no difference in the age, gender, racial, and regional profiles of the two groups as well. There are some notable differences in the two types of counties. Most striking, of course, is the difference in their size. The average beneficiary in a below-threshold county lives in a significantly smaller MSA than one in an above- 
threshold county. This is relevant because other work shows that small urban areas had fewer MA options than large areas even before urban floors were established (Pope et al. 2006, Table 3-4). There are other relevant differences between the groups, also likely related to size. Above-threshold counties have higher (beneficiary-weighted) Medicare enrollment and median income $(\$ 47,300$ versus $\$ 44,500, p=0.023)$, although their poverty rates are not statistically distinguishable at conventional levels. Their residents are also more likely to be admitted to larger hospitals (100-299 and 300+ beds, versus $<100$ beds). The extent to which these factors explain differences in MA enrollment or outcomes is an important question to which we now turn.

\section{Econometric models and results}

Our models specify the hospitalization or mortality during 2009 of beneficiary $i=$ $1, \ldots, \mathrm{N}_{z c}$ in zip code $z=1, \ldots, \mathrm{Z}$ that lies in county $c=1, \ldots, \mathrm{C}, Y_{i z c}$, as a function of MA enrollment status, health and demographic characteristics, and zip-code and county characteristics:

$$
Y_{i z c}=\alpha+\beta M A_{i z c}+X_{i z c} \gamma+H_{c z} \delta+W_{c} \eta+u_{i z c}
$$

where

$Y_{i z c}$ is an indicator $=1$ if the beneficiary had a hospital admission, an ACS admission, or death in 2009;

$M A_{i z c}$ is an indicator $=1$ if the beneficiary was enrolled in MA for all of 2009;

$X_{i z c} \quad$ is the CMS risk score and indicator variables for the age $(70-74,75-79,80-89,90$ 99, omitted group is 65-69) gender, and race of the beneficiary;

$H_{z c} \quad$ represents zip-code level hospital market characteristics, including the HHI, a hospital capacity index, and the density of for-profit, non-profit (omitted group is 
public), teaching, system, 100-299 bed and 300+ bed (omitted group is $<100$ bed) hospitals;

$W_{c} \quad$ contains the county's number of Medicare beneficiaries in 2009 (and its square and cube), its 2009 median income and other county-level characteristics in 2009, and its MSA's population in 2000 (on which its floor status is based, and its square and cube); and

$u_{i z c} \quad$ is an error term that we allow to be arbitrarily correlated within each county. OLS estimates from this model identify the effect of MA on $Y_{i z c}$ only under the assumption that MA enrollment decisions are uncorrelated with $u_{i z c}$, which is likely to be incorrect. For this reason we specify the MA enrollment decision as a logit model of $X_{i z c}$, $H_{z c}, W_{c}$, and $Z_{c}$, where $Z_{c}$ is an indicator $=1$ if county $c$ is in an MSA with population of 250,000 or more:

$$
\operatorname{Pr}\left(M A_{i z c}=1\right)=\frac{\exp \left(\lambda+X_{i z c} \pi+H_{z c} \tau+W_{c} \rho+Z_{c} \theta+v_{i z c}\right)}{1+\exp \left(\lambda+X_{i z c} \pi+H_{z c} \tau+W_{c} \rho+Z_{c} \theta+v_{i z c}\right)},
$$

and $v_{i z c}$ is an error term that we allow to be arbitrarily correlated within each county. We follow Wooldridge (2010, section 21.4.1.) and estimate (1) by instrumental variables, using as instruments $X_{i z c}, H_{z c}, W_{c}$, and $M A h a t_{i z c}$, where $M A h a t_{i z c}$ are the predicted values from (2). We also present OLS estimates of (1) for comparison.

Finally, we estimate placebo models in order to investigate the validity of the assumptions underlying our IV strategy. We present OLS and IV estimates of (1) and (2) using DIED2000 $i z c$ and $M A 2000_{i z c}$, respectively, as dependent variables. DIED2000 izc is defined for the cohort of beneficiaries enrolled in either MA or FFS Medicare for all 12 months in the year 2000, DIED2000 $i z c=1$ if beneficiary $i$ died in 2000, 0 otherwise; 
$M A 2000_{i z c}=1$ if beneficiary $i$ was enrolled in MA for all 12 months of $2000 .^{7}$ Because the urban payment floor did not take effect until 2001, in the absence of unobserved differences in beneficiary health or the medical care environment between above- versus below-threshold counties, there should be no effect of floor status on MA enrollment, and in turn no negative IV effect of MA on DIED2000 ${ }_{i z c}$.

Table 2 presents estimated marginal effects from (2), the logit of MA enrollment on $X_{i z c}, H_{z c}, W_{c}$, and $Z_{c}$. For ease of interpretation, all effects in this and subsequent tables are measured in percentage points, i.e., on a scale from 0 to 100 . The table reports heteroscedasticity-consistent standard errors allowing for arbitrary clustering within counties. The first row of the table shows that counties above the 250,000 population threshold have significantly greater MA enrollment, with a marginal effect evaluated at the mean of the other variables of 4.7 percentage points. The effect of the other covariates is consistent with previous research. High-risk and older beneficiaries are significantly less likely to enroll in MA; female, black, and beneficiaries from poorer MSAs are significantly more likely to enroll. With these estimates, we construct a predicted probability of enrollment in MA for each beneficiary which we use as an instrument to estimate equation (1).

Table 3 presents selected OLS and IV estimates from equation (2), the effect of MA on hospital admissions, ACS admissions, and mortality. ${ }^{8}$ MA enrollment reduces the rate of admission to the hospital in general and for ACS conditions. According to the IV estimates in column (2), MA reduces the probability of admission by 3.4 percentage

\footnotetext{
${ }^{7}$ The variables $X_{i z c}, W_{c}$, and $Z_{c}$ are defined as above, except a) they are based on 2000 data and b) exclude the CMS risk score, which did not exist and cannot be calculated for 2000 . We substitute conventional county-level measures of hospital market competitiveness and other market characteristics $\left(H_{c}\right)$ based on hospital bed shares from the year 2000 because we did not have sufficient information to calculate $H_{z c}$.

${ }^{8}$ We report estimates for covariates that differed significantly above versus below the floor threshold.
} 
points (standard error 1 percentage point). On a base admission rate of 16.9 percentage points (table 1), this amounts to a 22 percent reduction. Part of the effect of MA on admissions arises out of its impact on ACS conditions; MA reduces the probability of an ACS admission by 0.69 percentage points (standard error 0.38 percentage points, significant at the 10 percent level). There is also a significant IV effect of MA on mortality of 0.7 percentage points (column (6), standard error 0.19 percentage points); on a base of 4.6 percentage points, this amounts to a 15 percent reduction. Although the IV estimates are smaller than the OLS estimates, they are not statistically distinguishable from them at conventional levels, based on the IV standard errors. Of the other covariates, only the CMS risk score has a uniformly significant effect, suggesting that most of the impact of differences in the other covariates in above- versus below-threshold counties are accounted for by the polynominals in area size.

Table 4 presents results from placebo models of (1) and (2). They show results from models of the probability of enrollment in MA in the year 2000, and the OLS and IV effects of MA on mortality in 2000, using as an instrument the predicted probability of enrollment based on what the floor status of each year-2000 beneficiary's county would have been, had the urban floor then been in effect. These estimates have no causal interpretation, since the instrument on which they are based is by definition invalid. Instead, they are intended as a diagnostic test for the presence of unobserved differences in the probability of MA enrollment and beneficiary health in the year 2000 between above- and below-threshold counties. None of the year 2000 models include controls for the CMS risk score, since risk adjustment did not begin until 2004.

These tests suggest that the instrument is picking up the incentive effects of the benchmark on enrollment and is otherwise uncorrelated with unobserved determinants of 
health. According to column (1), there is no significant or economically important effect on MA enrollment of residing in an above-threshold county in the year 2000, before the payment change was implemented. The positive coefficient on MA in column (3) is inconsistent with the hypothesis that beneficiaries in above-threshold counties had better health in 2000; if anything, it suggests that the opposite is true. To the extent that arealevel differences in health are time-invariant, this finding suggests that our IV strategy understates (in absolute value) the true effect of MA.

We also reestimated the IV models underlying Table 3 excluding the risk score to investigate whether our estimated effects might be due to endogeneity in the score's determination. If MA plans encourage more intensive coding, and more intensive coding leads to higher risk scores, estimates of the effect of MA conditional on risk score would be inconsistent. The inconsistency arises because of positive correlation between measurement error in the risk score and the instrument; overstated risk scores for MA beneficiaries would make MA appear to have a greater beneficial effect on health than it actually did. However, we found no evidence to support this hypothesis. IV estimates of the models underlying Table 3 excluding the risk score were of approximately the same magnitude, although their standard errors were larger, reflecting the larger variance of the residual in equation (1).

\section{Conclusion}

Medicare currently allows beneficiaries to choose between a government-run health plan known as Traditional Medicare (TM), and privately-administered plans, known as Medicare Advantage (MA). Assessing the relative performance of TM and MA is an important issue, with first-order implications for not only national health and 
fiscal policy but also economic theory. However, because enrollment in MA is optional, evaluating the MA program is difficult. Beneficiaries who choose MA are observably healthier than those who choose TM. Because observational data on health is notoriously incomplete, and unobservable differences are likely positively correlated with observables, conventional analysis of MA's impact are potentially subject to selection bias -- bias that would tend to make MA look more efficient than it actually is.

In this paper, we offer a new approach to identifying the effects of MA. We use a discontinuity in the rules governing MA payments to private health plans that gives greater payments to plans that cover beneficiaries who live in counties that are part of Metropolitan Statistical Areas (MSAs) with populations of 250,000 or more. The sharp difference in payment rates at this population cutoff creates a greater incentive for plans to enroll beneficiaries in MA in counties just above versus just below the cutoff. The induced incremental enrollment, in turn, allows us to identify the effect of MA on the use of health services and the quality of care.

We find that the higher payment rate in these "urban floor" counties leads to significantly higher MA enrollment. In turn, payment-induced MA enrollment leads to statistically significantly lower rates of hospitalization and lower mortality. These findings support the hypothesis that MA provides better care than TM.

Our findings are consistent with recent regression-based estimates of the effect of MA. Landon et al. (2012), for example, find significantly fewer admissions per beneficiary in MA versus TM in 2009 using a matching algorithm; although our IV estimates are larger than their estimates, they are not statistically distinguishable. Dowd et al. (2011) find lower mortality in MA plans in the 1990s, although their selectioncorrected estimates show a much larger effect on mortality than do ours. 
Because our identification strategy depends crucially on the assumption that county floor status is uncorrelated with unobserved determinants of service use and health, we conducted placebo tests to investigate its validity as an IV. We estimated the effect of county floor status on MA enrollment, and the effect MA on mortality, in the year 2000. In the absence of correlation between the instrument and unobservables, there should be no effect of MA: the payment increases due to the floor didn't take effect until 2001. We found no evidence that beneficiaries from counties that later had discontinuously higher payment rates were more likely to enroll in MA, healthier, or less likely to need hospital care -- if anything, the opposite appears to be true.

Although we find that MA leads to fewer hospitalizations and less mortality, we cannot say that MA is more efficient than TM. Because the incremental MA enrollment underlying our estimates is induced by higher payment rates, we cannot determine whether the superior care received by MA enrollees is due to better management by private health plans or to the additional services provided to beneficiaries as a result of the higher rates. Indeed, other work has found increasing payment to MA plans reduces the rate at which their beneficiaries are hospitalized for certain conditions, which suggests that the latter mechanism may be relevant (Nicholas 2011). By implication, we cannot say whether MA plans would provide better care than TM, were they to be paid less than they were in 2009. This limitation of our study design is important. The ACA significantly reduces payments to MA plans in the future, especially those in areas with benchmarks that are above TM spending levels -- which is obviously related to county floor status. For this reason, our findings cannot be directly extrapolated to the future performance of MA. 
However, our estimates can be used as a starting point to bound MA's efficiency gains and inform current policy. To determine whether MA is more efficient than TM from a social perspective requires a comparison of the marginal expenditure/benefit ratios in the two programs. To derive this from our estimates for MA, the key question is the share of floor-induced increases in the benchmark that represent real resources consumed by health plans or beneficiaries, in the form of MA plan management expenses or additional services that contribute to health, versus the share that are transfers, in the form of funds returned to Medicare (i.e., the $25 \%$ of the difference between the bid and the benchmark), gains to plans' shareholders, lower MA premiums or cost sharing for beneficiaries, broader MA provider networks, or services like vision coverage (which, although they may provide utility, do not directly reduce mortality or otherwise improve conventional measures of health outcomes). If we assume that all of the $\$ 48 / \mathrm{month}$ increase in the benchmark (the difference between the benchmark in above- versus below-threshold counties, table 1) due to the floor represents real resource use, and the only relevant measure of benefit is avoided mortality, then the MA expansion we examine would be efficient as long as TM's marginal expenditure/benefit ratio were greater than approximately $\$ 165,000$ per year of life saved, since MA spent $\$ 576$ (= $\$ 48 * 12)$ per year to get approximately 3.5 fewer deaths per thousand beneficiary-years (= 0.0070 calendar-year mortality reduction from table 3 / 2).

For several reasons, this understates the cost-effectiveness of MA. First, it attributes no direct benefit to patients from the decrease in hospitalizations we observe, over and above any effect on mortality. Second, it assumes that no mortality benefits persist beyond 6 months on average. Third, it assumes none of the increase in the benchmark is returned to Medicare, and none represents a transfer to beneficiaries or 
plans. Nonetheless, the underlying calculations illustrate the sort of information that would be necessary in order to assess more precisely the benefits of expanding MA.

For purposes of policy, the key question is how much of the gains from MA that we observe could be achieved in the absence of increased government outlays in the form of the higher benchmark. This is related (although not identical) to the question above. To the extent that spending increases attributable to the urban floor represent transfers, the gains from expanding MA could be achieved without them, at least in theory. If all of the increases were transfers, none would be necessary to obtain the quality improvements that we found, as long as beneficiaries could be otherwise induced into the program by (for example) making TM less attractive.

Future research, along the lines of Song, Landrum, and Chernew (2012), might seek to estimate or simulate the value of these parameters. Future work should also seek to evaluate the performance of MA in the post-ACA world, where payments to MA plans will be less generous on average than they were historically, and the performance of MA under competitive bidding. Finally, future research might seek to investigate how MA interacts with the competitiveness of hospital, physician, and insurance markets, to determine the circumstances under which the gains from MA that we find would be most likely to be achievable. 
Table 1: Means and (Standard Deviations) of Variables Used in Analysis

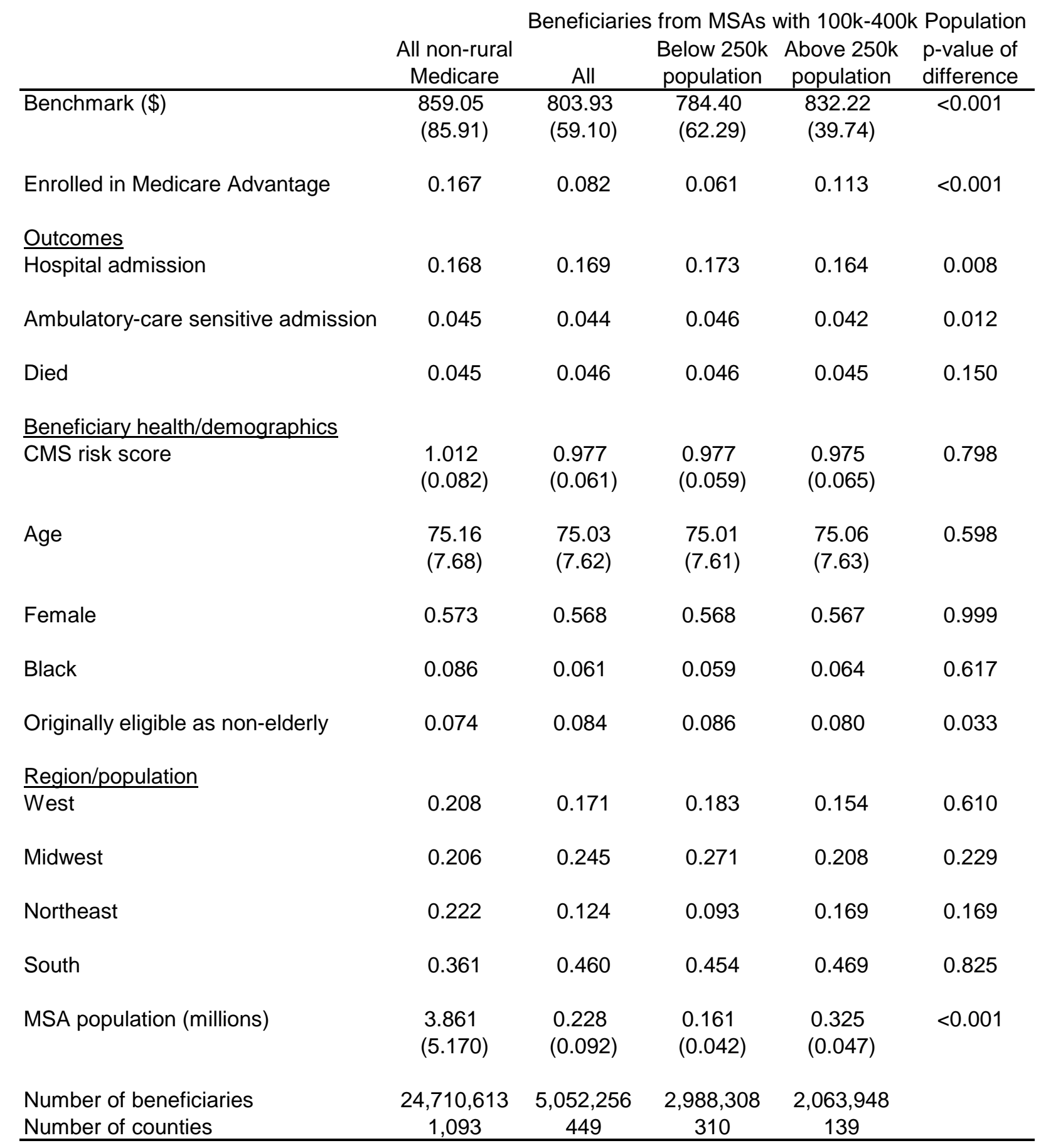


Table 1: Means and (Standard Deviations) of Variables Used in Analysis (continued)

\begin{tabular}{|c|c|c|c|c|c|}
\hline & $\begin{array}{c}\text { All non-rural } \\
\text { Medicare }\end{array}$ & $\begin{array}{c}\text { Beneficiarie } \\
\text { All } \\
\end{array}$ & $\begin{array}{c}\text { from MSAs } \\
\text { Below } 250 \mathrm{k} \\
\text { population }\end{array}$ & $\begin{array}{c}\text { with } 100 \mathrm{k}-400 \\
\text { Above } 250 \mathrm{k} \\
\text { population }\end{array}$ & $\begin{array}{l}\text { Population } \\
\text { p-value of } \\
\text { difference }\end{array}$ \\
\hline \multicolumn{6}{|l|}{ County characteristics } \\
\hline Medicare beneficiaries (millions) & $\begin{array}{c}0.106 \\
(0.015)\end{array}$ & $\begin{array}{c}0.021 \\
(0.001)\end{array}$ & $\begin{array}{c}0.016 \\
(0.009)\end{array}$ & $\begin{array}{c}0.029 \\
(0.002)\end{array}$ & $<0.001$ \\
\hline Doctors/1000 pop & $\begin{array}{l}2.591 \\
(1.521)\end{array}$ & $\begin{array}{l}2.149 \\
(1.693)\end{array}$ & $\begin{array}{l}2.143 \\
(1.948)\end{array}$ & $\begin{array}{l}2.157 \\
(1.234)\end{array}$ & 0.935 \\
\hline Specialist doctors/1000 pop & $\begin{array}{l}1.564 \\
(0.973)\end{array}$ & $\begin{array}{l}1.211 \\
(1.029)\end{array}$ & $\begin{array}{l}1.197 \\
(1.170)\end{array}$ & $\begin{array}{l}1.232 \\
(0.779)\end{array}$ & 0.746 \\
\hline Median income (100000 \$) & $\begin{array}{l}0.542 \\
(0.135)\end{array}$ & $\begin{array}{l}0.457 \\
(0.079)\end{array}$ & $\begin{array}{l}0.445 \\
(0.070)\end{array}$ & $\begin{array}{c}0.473 \\
(0.089)\end{array}$ & 0.023 \\
\hline Poverty Rate & $\begin{array}{l}0.136 \\
(0.048)\end{array}$ & $\begin{array}{l}0.155 \\
(0.045)\end{array}$ & $\begin{array}{l}0.158 \\
(0.046)\end{array}$ & $\begin{array}{l}0.151 \\
(0.042)\end{array}$ & 0.196 \\
\hline \multicolumn{6}{|c|}{ Kessler/McClellan (2000) zip code characteristics } \\
\hline $\mathrm{HHI}$ & 0.194 & 0.315 & 0.327 & 0.297 & 0.073 \\
\hline Hospital capacity index & 0.348 & 0.334 & 0.333 & 0.335 & 0.951 \\
\hline For-profit & 0.165 & 0.164 & 0.166 & 0.162 & 0.873 \\
\hline Non-profit & 0.758 & 0.730 & 0.723 & 0.739 & 0.656 \\
\hline Teaching & 0.545 & 0.422 & 0.403 & 0.449 & 0.205 \\
\hline System & 0.658 & 0.600 & 0.590 & 0.613 & 0.462 \\
\hline 100-299 bed hospital & 0.718 & 0.734 & 0.758 & 0.700 & 0.047 \\
\hline $300+$ bed hospital & 0.190 & 0.119 & 0.083 & 0.171 & 0.002 \\
\hline Number of beneficiaries & $24,710,613$ & $5,052,256$ & $2,988,308$ & $2,063,948$ & \\
\hline Number of counties & 1,093 & 449 & 310 & 139 & \\
\hline
\end{tabular}




\section{Table 2: Selected Logit Estimates from First Stage Determinants of MA Enrollment, 2009 Marginal Effects Reported in Percentage Points}

\begin{tabular}{|c|c|c|c|}
\hline $\begin{array}{l}\text { County in MSA with } \\
\text { above } 250 \mathrm{k} \text { population }\end{array}$ & $\begin{array}{l}4.680 \text { ** } \\
(2.184)\end{array}$ & & \\
\hline Beneficiary health/demographics & & County characteristics & \\
\hline CMS risk score & $\begin{array}{l}-91.173 * * * \\
(7.945)\end{array}$ & $\begin{array}{l}\text { MSA population } \\
\left(10^{\wedge}-5\right)\end{array}$ & $\begin{array}{r}17.064 \\
(15.808)\end{array}$ \\
\hline Age $70-74$ & $\begin{array}{r}0.036 \\
(0.081)\end{array}$ & $\begin{array}{l}\text { MSA population^2 } \\
\left(10^{\wedge}-10\right)\end{array}$ & $\begin{array}{r}-9.713 \\
(7.141)\end{array}$ \\
\hline Age $75-79$ & $\begin{array}{r}0.066 \\
(0.139)\end{array}$ & $\begin{array}{l}\text { MSA population^3 } \\
\left(10^{\wedge}-15\right)\end{array}$ & $\begin{array}{r}1.493 \\
(0.973)\end{array}$ \\
\hline Age $80-89$ & $\begin{array}{l}-0.626 * * * \\
(0.162)\end{array}$ & Doctors/1000 pop & $\begin{array}{r}-2.764 \\
(2.232)\end{array}$ \\
\hline Age $90-99$ & $\begin{array}{l}-1.309 * * * \\
(0.222)\end{array}$ & Specialist docs/1000 pop & $\begin{array}{r}4.303 \\
(3.522)\end{array}$ \\
\hline Female & $\begin{array}{l}0.4744^{* * *} \\
(0.109)\end{array}$ & Median income (100000 \$) & $\begin{array}{l}-25.300 * * \\
(10.000)\end{array}$ \\
\hline Black & $\begin{array}{l}1.358 * * * \\
(0.517)\end{array}$ & Poverty rate & $\begin{array}{r}2.916 \\
(15.000)\end{array}$ \\
\hline Region & & Zip code characteristics & \\
\hline West & $\begin{array}{r}1.261 \\
(1.780)\end{array}$ & $\mathrm{HHI}$ & $\begin{array}{l}-21.601 * * * \\
(3.876)\end{array}$ \\
\hline Midwest & $\begin{array}{r}0.869 \\
(1.159)\end{array}$ & Hospital capacity index & $\begin{array}{r}-0.618 \\
(2.000)\end{array}$ \\
\hline \multirow[t]{2}{*}{ Northeast } & $\begin{array}{l}13.783 \text { ** } \\
(6.459)\end{array}$ & 100-299 bed hospital & $\begin{array}{r}6.122 \\
(3.798)\end{array}$ \\
\hline & & $300+$ bed hospital & $\begin{array}{l}11.201 * * * \\
(4.052)\end{array}$ \\
\hline
\end{tabular}

Notes: Heteroscedasticity-consistent standard errors allowing for county clustering in parentheses. $\mathrm{N}=5,052,256$; number of counties $=449 .{ }^{*}, * *, * * *$ denote statistical significance at the 10,5 and 1 percent levels, respectively. 
Table 3: Effects of MA on Hospital Admissions and Mortality, 2009

Reported in Percentage Points

\begin{tabular}{|c|c|c|c|c|c|c|}
\hline & \multicolumn{4}{|c|}{$\begin{array}{l}\text { Ambulatory-care Sensitive } \\
\text { Admission }\end{array}$} & \multicolumn{2}{|c|}{ Died } \\
\hline & $\begin{array}{l}\text { OLS } \\
(1)\end{array}$ & $\begin{array}{l}\text { IV } \\
(2)\end{array}$ & $\begin{array}{l}\text { OLS } \\
(3)\end{array}$ & $\begin{array}{l}\text { IV } \\
(4)\end{array}$ & $\begin{array}{l}\text { OLS } \\
(5)\end{array}$ & $\begin{array}{l}\text { IV } \\
(6)\end{array}$ \\
\hline Enrolled in Medicare Advantage & $\begin{array}{l}-4.218 \text { *** } \\
(0.425)\end{array}$ & $\begin{array}{l}-3.415^{* \star *} \\
(1.042)\end{array}$ & $\begin{array}{l}-1.397^{\star \star \star} \\
(0.120)\end{array}$ & $\begin{array}{l}-0.693 \text { * } \\
(0.384)\end{array}$ & $\begin{array}{l}-0.792^{* \star *} \\
(0.057)\end{array}$ & $\begin{array}{l}-0.702 \text { *** } \\
(0.188)\end{array}$ \\
\hline CMS risk score & $\begin{array}{l}11.290 \\
(2.113)\end{array}$ & $\begin{array}{l}12.5377^{\star \star \star} \\
(2.881)\end{array}$ & $\begin{array}{l}5.160 * \star \star \\
(0.833)\end{array}$ & $\begin{array}{l}6.2544^{\star \star \star} \\
(1.156)\end{array}$ & $\begin{array}{l}1.633^{* \star \star} \\
(0.388)\end{array}$ & $\begin{array}{l}1.772 \text { *** } \\
(0.515)\end{array}$ \\
\hline \multicolumn{7}{|l|}{ County characteristics } \\
\hline $\begin{array}{l}\text { MSA population } \\
\left(10^{\wedge}-5\right)\end{array}$ & $\begin{array}{r}6.561 \\
(4.454)\end{array}$ & $\begin{array}{r}6.606 \\
(4.459)\end{array}$ & $\begin{array}{l}2.894 \text { * } \\
(1.704)\end{array}$ & $\begin{array}{l}2.933 \text { * } \\
(1.719)\end{array}$ & $\begin{array}{r}1.064 \\
(0.873)\end{array}$ & $\begin{array}{r}1.069 \\
(0.868)\end{array}$ \\
\hline $\begin{array}{l}\text { MSA population^ } 2 \\
\left(10^{\wedge}-10\right)\end{array}$ & $\begin{array}{l}-3.103 \\
(1.945)\end{array}$ & $\begin{array}{r}-3.104 \\
(1.942)\end{array}$ & $\begin{array}{l}-1.425 * \\
(0.742)\end{array}$ & $\begin{array}{l}-1.426 * \\
(0.749)\end{array}$ & $\begin{array}{r}-0.499 \\
(0.394)\end{array}$ & $\begin{array}{r}-0.499 \\
(0.393)\end{array}$ \\
\hline $\begin{array}{l}\text { MSA population^3 } \\
\left(10^{\wedge}-15\right)\end{array}$ & $\begin{array}{r}0.431 \\
(0.266)\end{array}$ & $\begin{array}{r}0.429 \\
(0.265)\end{array}$ & $\begin{array}{l}0.208 \text { ** } \\
(0.101)\end{array}$ & $\begin{array}{l}0.206 \text { ** } \\
(0.102)\end{array}$ & $\begin{array}{r}0.076 \\
(0.055)\end{array}$ & $\begin{array}{r}0.076 \\
(0.055)\end{array}$ \\
\hline $\begin{array}{l}\text { Median income } \\
(100000 \$)\end{array}$ & $\begin{array}{r}-2.380 \\
(2.740)\end{array}$ & $\begin{array}{r}-2.050 \\
(2.790)\end{array}$ & $\begin{array}{r}-0.097 \\
(1.060)\end{array}$ & $\begin{array}{r}0.195 \\
(1.070)\end{array}$ & $\begin{array}{l}-1.790 * * \star \\
(0.536)\end{array}$ & $\begin{array}{l}-1.750 * * * \\
(0.535)\end{array}$ \\
\hline Poverty rate & $\begin{array}{r}-0.781 \\
(4.231)\end{array}$ & $\begin{array}{r}-0.866 \\
(4.251)\end{array}$ & $\begin{array}{l}3.726 \text { ** } \\
(1.800)\end{array}$ & $\begin{array}{l}3.652 \text { ** } \\
(1.814)\end{array}$ & $\begin{array}{l}-1.577 * \\
(0.899)\end{array}$ & $\begin{array}{l}-1.587 * \\
(0.901)\end{array}$ \\
\hline \multicolumn{7}{|l|}{ Zip code characteristics } \\
\hline 100-299 bed hospital & $\begin{array}{r}1.688 \\
(1.259)\end{array}$ & $\begin{array}{r}1.592 \\
(1.267)\end{array}$ & $\begin{array}{l}1.152 \text { ** } \\
(0.503)\end{array}$ & $\begin{array}{l}1.068 \text { ** } \\
(0.519)\end{array}$ & $\begin{array}{r}-0.296 \\
(0.294)\end{array}$ & $\begin{array}{r}-0.307 \\
(0.295)\end{array}$ \\
\hline $300+$ bed hospital & $\begin{array}{c}2.530 \text { * } \\
(1.351)\end{array}$ & $\begin{array}{c}2.380 \text { * } \\
(1.364)\end{array}$ & $\begin{array}{l}1.4211^{\star \star \star} \\
(0.551)\end{array}$ & $\begin{array}{l}1.290 \text { ** } \\
(0.566)\end{array}$ & $\begin{array}{r}-0.169 \\
(0.315)\end{array}$ & $\begin{array}{l}-0.186 \\
(0.315)\end{array}$ \\
\hline
\end{tabular}

Notes: See Table 2. 
Table 4: Placebo Tests

Effects Reported in Percentage Points

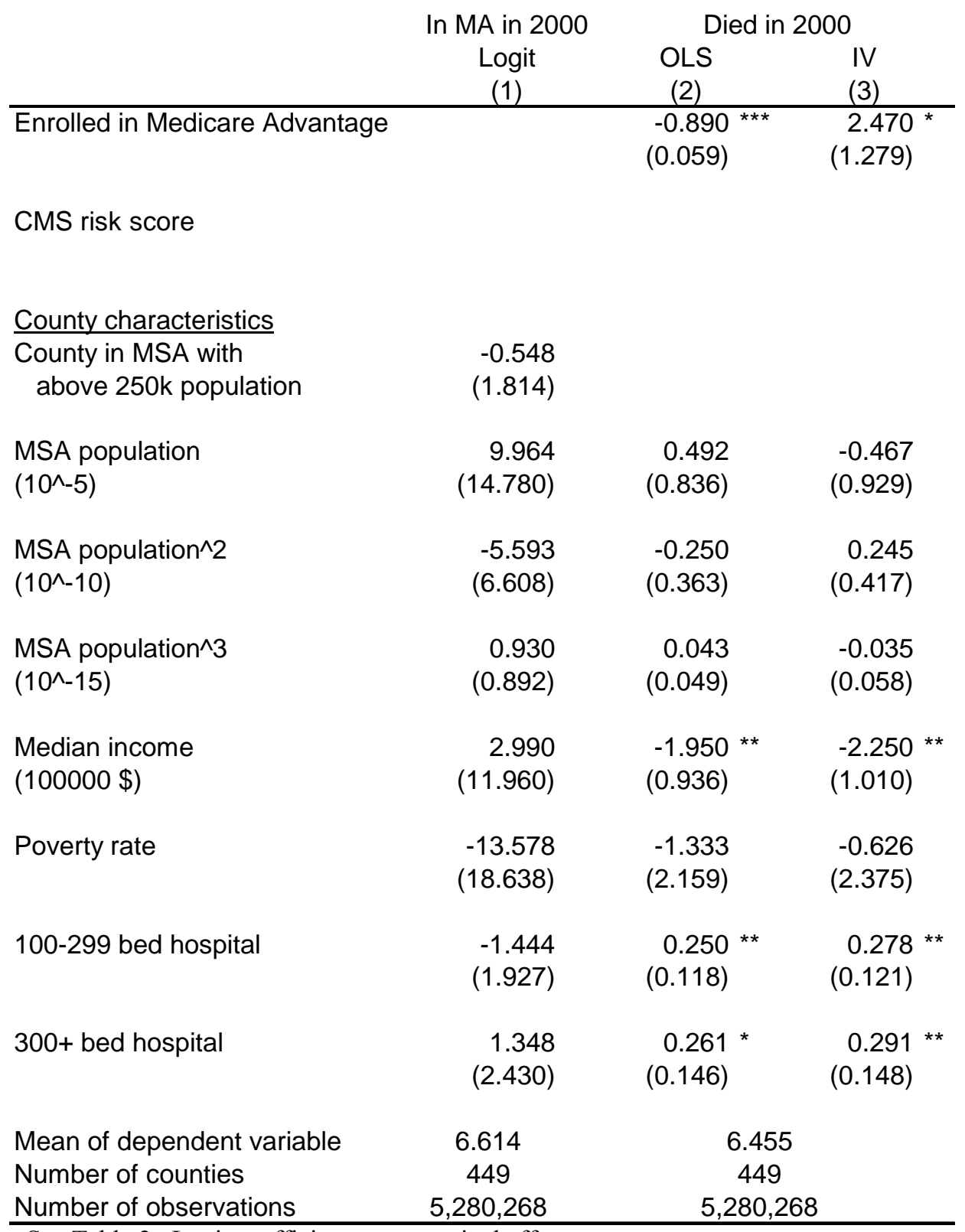

Notes: See Table 2. Logit coefficients are marginal effects. 


\section{$\underline{\text { References }}$}

Aizer, Anna, Janet Currie, and Enrico Moretti, Does Managed Care Hurt Health?

Evidence from Medicaid Mothers, 2007. Review of Economics and Statistics 89(3):38599.

Basu, Jayasree and Lee Rivers Mobley, Medicare Managed Care plan Performance: A Comparison Across Hospitalization Types, 2012. Medicare and Medicaid Research Review 2(1): E1-E19.

Centers for Medicare and Medicaid Services (CMS), Data Compendium: 2011 Edition, 2010, available at http://www.cms.gov/Research-Statistics-Data-and-Systems/StatisticsTrends-and-Reports/DataCompendium/2011_Data_Compendium.html.

Cohen, Robb, Jeff Lemieux, Jeff Schoenborn, et al., Medicare Advantage Chronic Special Needs Plan Boosted Primary Care, Reduced Hospital Use Among Diabetes Patients, 2012. Health Affairs 31(1):110-19.

Congressional Budget Office, Supplemental Data: The 2012 Long Term Budget Outlook, 2012, available at http://www.cbo.gov/sites/default/files/cbofiles/attachments/43288LTBOSuppTables_0.xls.

Dowd, Bryan, Matthew Maciejewski, Heidi O'Connor, et al., Health Plan Enrollment and Mortality in the Medicare Program, 2011. Health Economics 20:645-59.

Duggan, Mark, Does Contracting out increase the efficiency of government programs? Evidence from Medicaid HMOs, 2004. Journal of Public Economics 88:2549-72.

Kaiser Family Foundation, Fact Sheet: Medicare Advantage, 2012, available at http://www.kff.org/medicare/uplaod/2052-16.pdf.

Keenan, Patricia, Marc Elliott, Paul Cleary, et al., Quality Assessments by Sick and Healthy Beneficiaries in Traditional Medicare and Medicare Managed Care, 2009. Medical Care 47(8):882-8.

Kruzikas, D.T., H.J. Jiang, D. Remus, et al., Preventable Hospitalizations: A Window Into Primary and Preventive Care, 2000. Health Care Cost and Utilization Project Fact Book No. 5, Agency for Health Care Research and Quality, Rockville, MD.

Landon, Bruce E., Alan Zaslavsky, Shulamit Bernard, et al., Comparison of Performance of Traditional Medicare vs. Medicare Managed Care, 2004, JAMA 291(14):1744-52.

Landon, Bruce, E., Alan Zaslavsky, Robert Saunders, et al., Analysis of Medicare Advantage HMOs Compared with Traditional Medicare Shows Lower Use of Many Services During 2003-09, 2012. Health Affairs 31(12):2609-17. 
Lemieux, Jeff, Cary Sennett, Ray Wang, et al., Hospital Readmission Rates in Medicare Advantage Plans, 2012. American Journal of Managed Care 18(2):96-104.

McGuire, Thomas G., Joseph Newhouse, and Anna Sinaiko, An Economic History of Medicare Part D, 2011. Milbank Quarterly 89(2):289-332.

Medicare Payment Advisory Commission (MedPAC), The Medicare Advantage Program: Status Report, (March) 2012a. In Report to the Congress: Medicare Payment Policy, Chapter 12, available at http://www.medpac.gov/chapters/Mar12_Ch12.pdf.

Medicare Payment Advisory Commission (MedPAC), Issues for Risk Adjustment in Medicare Advantage, (June) 2012b. In Report to the Congress: Medicare and the Health Care Delivery System, Chapter 4, available at http://www.medpac.gov/chapters/Jun12_Ch04.pdf.

Medicare Payment Advisory Commission (MedPAC), Payment Basics: Medicare Advantage Program Payment System, (October) 2012c, available at http://www.medpac.gov/documents/MedPAC_Payment_Basics_12_MA.pdf.

Nicholas, Lauren, Modeling the Impact of Medicare Advantage Payment Cuts on Ambulatory Care Sensitive and Elective Hospitalizations, 2011. Health Services Research 46(5):1417-35.

Pope, Gregory, Leslie Greenwald, Deborah Healy, et al., Impact of Increased Financial Incentives to Medicare Advantage Plans, (September) 2006. Prepared for Victor McVicker, CMS, RTI International, available at http://cms.hhs.gov/Research-StatisticsData-and-Systems/Statistics-Trends-and-Reports/Reports/downloads/Pope.pdf.

Shliefer, Andrei, State versus Private Ownership, 1998. Journal of Economic Perspectives 12(4):133-50.

Skinner, Jonathan, Eliot Fisher, and Jack Wennberg, The Efficiency of Medicare, 2005, in David Wise, ed., Analyses in the Economics of Aging, University of Chicago Press, 129-160.

Song, Zirui, Mary Beth Landrum, Michael Chernew, Competitive Bidding in Medicare: Who Benefits from Competition? 2012. American Journal of Managed Care 18(9):546552.

Wooldridge, Jeffrey, Econometric Analysis of Cross Section and Panel Data, 2d. ed, 2010. Cambridge, MA: MIT Press.

Zuckerman, Stephen, Aimee Williams, and Karen Stockley, Trends in Medicaid Physician Fees, 2003-2008, 2009. Health Affairs 28(3): w510-w519. 